\title{
Workshop Financial Literacy untuk Siswa SMA 6 Tangerang Selatan
}

\author{
Herlisianne Suyanto ${ }^{1 *}$, Dijan Mardiati ${ }^{2}$, R.Hendra Winarsa ${ }^{3}$, Widia Astusti ${ }^{4}$, Reza \\ Octovian $^{5}$ \\ 1,2,3,4,5 Program Studi Manajemen, Fakultas Ekonomi, Universitas Pamulang \\ Jl. Surya Kencana No.1, Pamulang Barat, Kec. Pamulang \\ Kota Tangerang Selatan, Banten 15417 \\ *Penulis Korespodensi: dosen01201@unpam.ac.id
}

\begin{abstract}
ABSTRAK
Kebutuhan manusia dalam ilmu ekonomi bisa dikatakan tidak terbatas adanya. Semua keinginan ingin sekali terealisasi dengan mudah. Kondisi ini tentusaja tidak akan bisa terwujud tanpa adanya pengaturan keuangan yang baik. Alasannya,dengan mengatur keuangan seseorang bisa memperioritaskan antara kebutuhan primer, skunder, dan tersier. Oleh sebab itulah pada PKM ini akan diberikan penyuluhan mengatur keuangan bagi anak, khususnya anak dalam usia sekolah (pelajar). Metode pelaksanaan dengan metode penyuluhan dan seminar. Pengelolaan keuangan sederhana di SMK mendapatkan hasil yang sangat baik. Siswa lebih peka terhadap diri dan ke mulai dapat mengambil sikap untuk menentukan apasaja yang harus diraih dan ditempuh untuk mewujudkan rencana keuangannya tersebut, meski belum terkondidikan dengan baik, mereka mampu memberikan pemaparan akan perncanaan keuangannya di masa yang akan datang.
\end{abstract}

Kata Kunci :Keuangan, Literasi

\begin{abstract}
Human needs in economics can be said to be unlimited. All wishes long to be realized easily. This condition certainly would not have been possible without good financial arrangements. The reason, by regulating one's finances can prioritize primary, secondary and tertiary needs. That is why the PKM will be given counseling to arrange financial management for children, especially children of school age (students). The method of implementation is using counseling and seminar methods. Simple financial management in SMKs gets very good results. Students are more sensitive to themselves and begin to take the attitude to determine what must be achieved and taken to realize the financial plan, although not well educated, they are able to give an explanation of their financial planning in the future.
\end{abstract}

Keywords: Finance, Literacy

\section{PENDAHULUAN}

Beberapa Siswa SMA 6 Tangerang Selatan memiliki minat berwirausaha yang tinggi. Hal itu ditunjukkan dengan kegiatan wirausaha yang dilakukan di lingkungan sekolah. Menjadi reseller, drop shiper atau bahkan endorser, baik untuk produk orang 
lain ataupun produk buatan sendiri. Fenomena tersebut menimbulkan budaya berwirausaha di lingkungan sekolah (Widiyatnoto, 2013). Sayangnya mayoritas siswa berwirausaha dengan kemampuan skill yang terbatas, sehingga baik pengalaman maupun profit yang didapatkan oleh mereka kebanyakan masih belum maksimal. Beberpa diantaranya masih kurangnya pemahaman dan pengetahuan para remaja khususnya siswa dalam mengelola keuangan mandiri, siswa yang memiliki kegiatan usaha dalam hal mengatur diri dan membuat perencanaan keuangan yang baik. Hal itu dikarenakan para siswa mayoritas masih belum memiliki pemahaman dan sikap dalam mengelola keuangan yang baik .

Sebagai salah satu SMA Unggulan di Tangerang Selatan, SMA 6 Tangerang Selatan berkewajiban membentuk mindset dan ketrampilan peserta didiknya agar mampu bersaing di era milenial saat ini. Salah satunya adalah dengan mengembangkan skill kewirausahaan para siswa. Agar Siswa dapat memiliki semangat berwirausaha yang terstruktur sejak dini, mampu memetakan diri dan dapat membuat branding diri dan produk yang dibuat

Identifikasi masalah yang ditemukan di lapangan adalah masih banyak siswa merasakan tekanan dalam finansial untuk saat ini dan masa depan. Lebih dari seperempat, atau sekitar 28 persen merasakan banyak kecemasan finansial sehingga berdampak dari kegiatan belajar yang sedang dijalani. Masalah keuangan membuat siswa mengalami stress dan memikirkannya terus-menerus, pola hidup konsumtif pada usaia remaja akan berdampak buruk juga dengan keuangan mereka. Dengan kecemasan yang berlebih, besar kemungkinan siswa malah mengambil keputusan yang salah. Seperti tidak sengaja menghabiskan uang.

Ditemukan masih kurangnya pemahaman dan pengetahuan para remaja khususnya siswa dalam mengelola keuangan mandiri, siswa yang memiliki kegiatan usaha dalam hal mengatur diri dan membuat perencanaan keuangan yang baik (Riski, Sulistianingsih, \& Masruri, 2019). Hal itu dikarenakan para anggota mayoritas masih belum memiliki pemahaman dan sikap dalam berorganisasi yang baik. Sehingga diperlukan penyuluhan mengenai pengelolaan keuangan sederhana. Agar siswa dapat megelola keuangan dengan baik, hal itu akan sangat membantu ketika seseorang yang menginjak masa dewasa awal, masa di mana secara psikologis jiwanya masih rentan untuk terpengaruh dan mudah berubah-ubah, hal utama yang menjadi konstentrasi adalah keuangan bagi para dewasa awal.Mengingat pengeluarannya juga akan besar karena gaya hidup pada masa ini lebih tinggi daripada anak-anak atau orang tua. Remaja yang berada pada masa ini mendapatkan pemasukan dari orang tua atau hasil bekerja. Sehingga harus dapat memanage keuangannnya dengan baik (Yuangga, Jasmani, Irmal, Supiyan, \& Rostikawati, 2020).

Masalah keuangan yang dihadapi siswa adalah pengeluaran lebih besar dibandingkan dengan uang bulanan yang didapat dari orangtua.Sebagai seorang siswa, sudah harus mulai melatih diri untuk bisa mandiri dan bisa mengatur keuangan sendiri tanpa campur tangan orangtua.Akan tetapi, masih banyak siswa yang kehabisan uang jajan sampai harus menahan lapar di akhir bulan.

Uang bulanan pemberian orang tua seringkali tidak bisa mencukupi semua kebutuhan dan memaksa siswa untuk mencari cara (biasanya pinjam uang ke teman) demi bertahan hingga bulan berikutnya. Siswa sangat konsumtif dalam berbelanjan, Tawaran diskon, apalagi dengan skema "potongan pada pembelian kesekian" 


\section{Herlisianne Suyanto, dkk}

mendorong seseorang untuk membeli barang-barang yang kurang esensial demi mengejar diskon. Alasannya, "suatu saat akan berguna" atau "kapan lagi dapat barang murah". Padahal setelah dihitung benar-benar-misalnya pada barang "A"-, perbedaan harga setelah mendapatkan diskon dengan sebelum diskon hanya berbeda sedikit saat membelinya satuan. Siswa seharusnya dapat belajar untukk lebij realistis pada jebakan-jebakan diskon yang ditawarkan. Tak lagi menjadi kalap, siswa akan lebih selektif pada barang yang benar-benar esensial, dengan atau tanpa diskon. Agar hal tersebut tidak terjadi, siswa perlu membuat anggaran keuangan dan disiplin mencatat keuangan setiap bulannya.

Sebagian siswa masih berpikir bahwa kegiatan mereka hanya sekadar belajar dan berpartisipasi dalam kegiatan sekolah yang tidak bisa menghasilkan uang.

Masalah keuangan siswa berikutnya adalah susahnya untuk menabung dan melakukan investasi dengan uang jajan bulanan. Dengan status siswa yang dimiliki terkadang membuat siswa berpikir santai dan merasa masih punya banyak waktu untuk mempersiapkan masa depan sehingga merasa tidak perlu rajin menabung.Padahal kebiasaan dari usia muda inilah yang akan menentukan kesuksesan financial mereka saat dewasa nanti.

Masalah keuangan siswa selanjutnya adalah tidak memiliki uang di saat-saat genting (Yuangga \& Jasmani, 2020). Misalnya, tiba-tiba guru mewajibkan seluruh siswa untuk membeli peralatan praktikum yang mahal. Atau tiba-tiba siswa jatuh sakit dan harus dirawat, sementara tidak punya uang yang cukup. Setiap orang tentu akan/telah melewati masa dewasa awal atau masa peralihan dari masa remaja. Masa dewasa awal terjadi saat usia kurang lebih 20 tahun. Saat memasuki masa tersebut, seseorang sudah mulai menemukan identitas dirinya. Banyak hal yang harus dipersiapkan seseorang untuk mmempersiapkan masa ini.

Berbagai macam perubahan juga terjadi pada diri seseorang yang sedang menginjak masa ini (Nasrudin, 2017). Mulai dari perubahan fisik, mental, pola pikir, dan lainnya. Salah satu yang terjadi pada masa ini yaitu rasa ketergantungan akan berkurang dan berubah menjadi rasa mandiri.

Perasaan untuk memiliki kebebasan menjalani kehidupan sendiri akan muncul . Persaingan mengenai masa depan pun akan berubah menjadi lebih realistis. Masa-masa ini menjadi salah satu masa paling krusial bagi setiap orang. Selain perubahan, banyak pula masalah mulai muncul seiring bertambahnya usia (Herlina, 2013).

Rasa mandiri dan perasaan ingin memiliki kebebasan menjadi salah satu hal yang harus diwaspadai dan mendapat perhatian lebih dari orang tua. Hal itu dapat terjadi pada semua bidang, salah satunya adalah mengenai keuangan (Herawati, 2015). Kemampuan dalam mengelola keuangan setiap orang berbeda-beda (Ardiana, 2017).

Beberapa ada yang memiliki kemampuan mengelola keuangan dengan baik, sisanya tidak. Padahal keuangan merupakan hal penting untuk melakukan aktifitas khususnya yang berhubungan dengan kegiatan jual beli.

Jika seseorang tidak dapat mengelola keuangannya dengan baik, uang yang milikinya bisa saja digunakan untuk sesuatu yang negatif dan akhirnya merusak kehidupan orang tersebut. Sebaliknya, jika keuangan dapat dikelola dengan baik, mencapai kesuksesan saat usia masih muda bukan tidak mungkin terjadi.

Untuk itulah tim dosen program studi Manajemen mengadakan Litrasi Keuangan sebagai bentuk kepedulian dan pengabdian kepada masyarakat kepada Siswa SMA 6 Tangerang Selatan. Pelatihan ini akan melakukan pendekatan kekinian sehingga dapat 
lebih mudah dipahami oleh siswa SMA 6 Tangerang Selatan yang rata-rata adalah pemuda dan remaja milenial yang up to date dengan keadaan saat ini.

\section{METODE PELAKSANAAN}

Pendidikan literasi keuangan di sekolah akan berjalan dengan baik ketika dilakukan dengan melibatkan berbagai pihak. OECD memberikan beberapa pedoman yang dapat diterapkan sebuah negara agar penerapan pendidikan literasi keuangan di bangku sekolah dapat berjalan dengan baik. Langkah - Langkah tersebut antara lain :

1. Pendidikan literasi keuangan di sekolah harus menjadi bagian dari strategi nasional terkoordinasi. Strategi ini harus memiliki payung hukum yang kuat atau koordinator untuk memastikan relevansi dan keberlanjutan jangka panjang. Sistem pendidikan dan profesi harus terlibat dalam pengembangan strategi.

2. Harus ada kerangka kerja pembelajaran yang memuat secara jelas tujuan, hasil belajar, konten, pendekatan pedagogis, sumber daya dan rencana evaluasi. Konten harus mencakup pengetahuan, keterampilan, sikap dan nilai-nilai. Kerangka kerja ini dapat nasional, regional atau lokal.

3. Sedapat mungkin, sumber berkelanjutan pendanaan harus diidentifikasi sejak awal.

4. Pendidikan keuangan harus dimulai sedini mungkin, idealnya sejak awal sekolah formal, dan melanjutkan sampai akhir waktu siswa di sekolah.

5. Pendidikan keuangan idealnya harus menjadi bagian inti dari kurikulum sekolah. Hal ini dapat, tetapi tidak perlu, diajarkan sebagai subjek yang "berdiri sendiri" namun bisa diintegrasikan ke dalam mata pelajaran lain seperti matematika, ekonomi, ilmu sosial atau kewarganegaraan. Pendidikan keuangan dapat memberikan berbagai konteks "kehidupan nyata" di berbagai mata pelajaran.

6. Guru harus cukup terlatih dan merupakan sumber daya yang dibuat sadar akan pentingnya pendidikan literasi keuangan dan memahami metode pedagogis yang relevan, dan mereka harus menerima dukungan dan pelatihan untuk mengajarkan pendidikan literasi keuangan.

7. Pendidikan literasi keuangan harus mudah diakses, objektif, berkualitas tinggi, dukungan alat-alat belajar yang efektif, sumber daya pedagogis yang tersedia untuk sekolah-sekolah dan guru yang sesuai dengan tingkat pendidikan.

8. Kemajuan siswa harus dinilai dan siswa harus mendapatkan pengakuan atas prestasi yang sudah mereka raih.

\section{HASIL DAN PEMBAHASAN}

Pengelolaan keuangan sederhana untuk siswa SMA 6 Tangerang Selatan diharapkan mampu memberikan visi dan semangat baru dalam upaya siswa meraih cita-cita. Pengelolaan keuangan sederhana ini adalah dasar yang akan digunakan oleh siswa untuk membentuk mindset, kemampuan berpikir hemat, cermat dan ekonomis. Sehingga akan berdampak pada perilakunya menggunakan uang baik di sekolah maupun di rumah.

Dengan pengelolaan keuangan yang mantab, siswa akan lebih bisa fokus dalam belajar, dapat mengatur diri dengan baik, memiliki tujuan yang pasti, serta akan 
Herlisianne Suyanto, dkk

membuatnya mampu berpikir secara rasional. Siswa akan lebih mengenal dirinya sendiri, potensi yang dimiliki serta upaya yang dapat dilakukan untuk meraih keinginannya dan dapat menikmati prosesnya dengan benar.

Group Disscusion yang digunakan sebagai model penyampaian materi dirasa sangat efektif, siswa lebih dapat terbuka dalam menyampaikan keresahannya tentang masa depan dengan suasana yang santai dan terbuka. Mencurahkan permasalahn keuangan yang ternyata tidaklah sederhana yang seperti perkiraan sebelumnya. Seluruh perserta diajak mengutarakan permasalahan untuk kemudian dipecahkan bersamasama. Kebanyakan siswa yang menjadi peserta masih belum memiliki dasar yang kuat dalam pengelolaan keuangan, sehingga gaya hidup mereka cenderung boros, impulsif dan menjadi generasi milenial yang sangat konsumtif.

Pengisian lembar kerja yang dilakukan individu, lebih banyak menyadarkan siswa tentang apa yang sebenarnya mereka inginkan, siapa mereka, dan apa yang mereka harapkan di masa yang akan datang. Pengisian itu dilakukan secara individu setelah siswa mendapatkan serangkaian materi tentang pengelolaan keuangan. Siswa diajak untuk membuka dirinya dan jujur mengenai keinginan di masa yang akan datang setelah diberikan waktu untuk membuat pos pengeluaran dengan cermat.

Pengelolaan keuangan sederhana di SMK mendapatkan hasil yang sangat baik. Siswa lebih peka terhadap diri dan ke mulai dapat mengambil sikap untuk menentukan apasaja yang harus diraih dan ditempuh untuk mewujudkan rencana keuangannya tersebut, meski belum terkondidikan dengan baik, mereka mampu memberikan pemaparan akan perncanaan keuangannya di masa yang akan dating

\section{PENUTUP}

Hasil kegiatan PKM di SMA 6 Tangerang Selatan berjalan dengan ancar. Siswa terlihat antusias mempelajari materi dalam kegiatan PKM Literasi keuangan, Pendidikan literasi keuangan harus dimulai sejak dini karena jika anak-anak mendapatkan pendidikan literasi keuangan sejak dini, maka mereka kelak akan memperoleh pembelajaran kumulatif. Akan tetapi, saat ini informasi dan pendidikan literasi keuangan bagi remaja sangatlah terbatas, bahkan kurikulum pendidikan di Indonesia belum memasukkan pendidikan literasi keuangan. Di beberapa negara, pendidikan literasi keuangan sudah terintegrasi dalam kurikulum pendidikan dasar.

Tingkat literasi keuangan dipengaruhi oleh tingkat pendapatan dan pendidikan orang tua. Remaja dari keluarga ekonomi lemah mempunyai tingkat literasi keuangan lebih rendah dibanding remaja dari keluarga ekonomi tinggi. Remaja dengan orang tua yang berpendidikan rendah, memiliki tingkat literasi keuangan yang lebih rendah dibanding mereka dengan orang tua berpendidikan tinggi. Sehingga menyerahkan pendidikan keuangan ke keluarga bukan merupakan solusi, karena tingginya kesenjangan tingkat pendidikan dan tingkat penghasilan di Indonesia.

\section{DAFTAR PUSTAKA}

Ardiana, M. (2017). KONTROL DIRI, PENDIDIKAN PENGELOLAAN

KEUANGAN KELUARGA, PENGETAHUAN INKLUSI KEUANGAN SISWA

PENGARUHNYA TERHADAP PERILAKU MENABUNG SISWA SMK SE

KOTA KEDIRI. JURNAL EKONOMI PENDIDIKAN DAN KEWIRAUSAHAAN. 
https://doi.org/10.26740/jepk.v4n1.p59-75

Herawati, N. T. (2015). Kontribusi pembelajaran di perguruan tinggi dan literasi keuangan terhadap perilaku keuangan mahasiswa. Jurnal Pendidikan Dan Pengajaran. https://doi.org/https://dx.doi.org/10.23887/jppundiksha.v48i1-3.6919

Herlina. (2013). PERKEMBANGAN MASA REMAJA (Usia 11/12 - 18 tahun). Mengatasi Masalah Anak Dan Remaja. https://doi.org/https://doi.org/10.1016/j.jvoice.2013.08.014

Nasrudin, M. (2017). Perkembangan Remaja. Journal INSTITUTIONAL REPOSITORY of IAIN Tulungagung (IRIT).

Riski, T. R., Sulistianingsih, H., \& Masruri. (2019). Literasi Keuangan dan Perilaku Keuangan Pada Mahasiswa Perguruan Tinggi Swasta X dikota Padang. Jurnal Manajemen Dan Kewirausahaan. https://doi.org/10.31317

Sunarsi, D., Kustini, E., Lutfi, A. M., Fauzi, R. D., \& Noryani, N. (2019). Penyuluhan Wirausaha Home Industry Untuk Meningkatkan Ekonomi Keluarga Dengan Daur Ulang Barang Bekas. BAKTIMAS: Jurnal Pengabdian pada Masyarakat, 1(4), $188-193$

Widiyatnoto, E. (2013). Pengaruh Jiwa Kewirausahaan Dan Budaya Keluarga Terhadap Minat Berwirausaha Pada Siswa Smkn 1 Wonosari Dan Smkn 2 Wonosari. Pendidikan.

Yuangga, K. D., \& Jasmani, J. (2020). The Influence of Self Control and Economic Literacy on Student Lifestyle (at Madrasah Aliyah Islamiyah Ciputat). PINISI Discretion Review. https://doi.org/10.26858/pdr.v1i2.13244

Yuangga, K. D., Jasmani, J., Irmal, I., Supiyan, D., \& Rostikawati, D. (2020). MENUMBUHKAN KEBIASAAN HIDUP CERMAT DENGAN MEMANFAATKAN CELENGAN DI LINGKUNGAN DESA CIDOKOM KECAMATAN GUNUNG SINDUR. Jurnal Pengabdian Dharma Laksana. https://doi.org/10.32493/j.pdl.v2i2.3985 